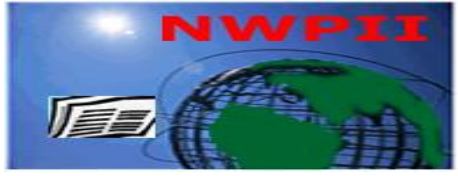

\title{
Apelin-13 Attenuates Ischemic Changes in A Rat Model of Myocardial Infarction via Increasing Circulating Angiogenic Factors
}

\begin{abstract}
Mona A. Said
Physiology department, Faculty of Medicine, Benha University, Egypt

"Corresponding Author

Mona A. Said

Physiology department, Faculty of Medicine

Benha University

Egypt

Email: dr.monaabdelazim@gmail.com

Mobile: 00201117060320

Received:01 October 2020; | Revised:22 October 2020; | Accepted:01 March 2021

\section{Abstract}

Ischemic heart disease is a global health concern in the present day with limited therapies. Extensive efforts have been devoted to find therapies that promote angiogenesis and enhance perfusion to the ischemic myocardium. The aim of the present study was to look into the effects of apelin-13 on circulating angiogenic factors after myocardial infarction in rats. Forty adult male rats were randomly assigned into four equal groups $(n=10)$; Sham operated, Sham operated + Apelin 13, myocardial infarction (MI) group and MI + Apelin 13. Infarction size, serum level of cardiac enzymes and serum levels of angiogenic factors; insulin like growth factor one (IGF-1), transforming growth factor-beta (TGF- $\beta$ ) and vascular endothelial growth factor (VEGF) were assessed 28 days after apelin administration. Compared to sham operated group, induction of myocardial infarction resulted in significant increase in infarction size from zero to $45.85 \pm$ 2.94, cardiac biomarkers (CK-MB and LDH) from $3.19 \pm 0.62 \mathrm{ng} / \mathrm{ml}$ and $24.87 \pm 3.48 \mathrm{IU} / \mathrm{L}$ to $27.75 \pm$ $1.24 \mathrm{ng} / \mathrm{ml}$ and $98.82 \pm 3.24 \mathrm{IU} / \mathrm{L}$ respectively $(\mathrm{P}<0.05)$ as well as serum angiogenic factors (IGF-1, VEGF and TGF- $\beta$ levels) as they were increased from $3.44 \pm 0.46 \mathrm{ng} / \mathrm{ml}, 6.33 \pm 0.88 \mathrm{ng} / \mathrm{ml}$ and 145.09 $\pm 4.80 \mathrm{pg} / \mathrm{ml}$ to $9.86 \pm 0.92,12.67 \pm 0.77$ and $338.77 \pm 9.56$ respectively. Apelin-13 treatment induced a significant increase in serum angiogenic factors and reduced the ischemic changes in the myocardium when compared to the MI group. These results indicated that apelin treatment protects against myocardial infarction via increased circulating angiogenic growth factors therefore, apelin may be a new therapeutic target in myocardial infarction.
\end{abstract}

Keywords: Apelin-13, Myocardial infarction, Angiogenesis 


\section{Introduction}

Myocardial infarction is a fundamental public health problem and the leading cause of mortality in both developed and developing countries. According to the world health organization (WHO) report, heart disease and stroke will become the leading causes of death and disability worldwide by the year $2025^{[1]}$. Hence, in light of the abovealarming statistics, researches on producing potent therapeutics for use in heart diseases are getting more focused ${ }^{[2]}$.

Myocardial infarction (MI) is an acute condition that occurs by occlusion of coronary artery, resulting in imbalance between coronary blood supply and myocardial demand, cardiac muscle damage and loss of cardiomyocytes ${ }^{[3]}$. Left anterior descending artery is the main blood-supply vessels for the left ventricle anterior wall, left ventricular lateral wall and interventricular septum. Coronary artery ligation of the left anterior descending coronary artery is the most commonly used method in the study of myocardial infarction and myocardial ischemia pharmacodynamics ${ }^{[4]}$.

An interesting hypothesis is that the development of new blood vessels from preexisting vascular bed (angiogenesis) or the remodeling of preexisting collaterals has the potential to salvage the ischemic myocardium and improve the outcome after AMI ${ }^{[5]}$. Angiogenic growth factors exert a major role in blood vessel formation by aiding cell proliferation, migration and adhesion. These growth factors are produced by various cell types and include a wide range of proteins like vascular endothelial growth factor (VEGF), transforming growth factor (TGF), fibroblast growth factor (FGF), platelet derived growth factor (PDGF), insulin like growth factor-1 (IGF-1), angiopoietins (Ang) and others ${ }^{[6]}$. A number of angiogenic growth factors are known to be expressed during MI ${ }^{[7]}$.

Although a number of drugs have been widely used to treat myocardial ischemia, the usefulness of these drugs has been limited due to their serious adverse effects, such as cardiac depression or proarrhythmic effects thus there is great interest in the development of new types of cardioprotective drugs, which may attenuate the effects of myocardial infarction in clinical practice ${ }^{[8]}$.
Apelin, a novel bioactive peptide, was initially identified as an endogenous ligand for the orphan $G$ protein-coupled, sharing similarities with the angiotensin II type 1 receptor pathway ${ }^{[9]}$. It was originally isolated from bovine stomach tissue extracts in 1998 by Tatemoto et al. ${ }^{[10]}$. Several active fragments of apelin have been identified (apelin-36, apelin-19, apelin-17, apelin-16, apelin13, and apelin-12). Apelin-13 and apelin-36 are considered the most active isoforms with the greatest activity on the cardiovascular homeostasis [11].

Apelin is expressed in various tissues like hearts, brain, lungs, kidneys, liver, gastrointestinal tract, adipose tissue, adrenal glands, endothelium and human plasma. It mediates a wide range of physiological and pathological functions including dilatation of arteries, systolic effect, powerful inotrope, regulation of fluid homeostasis, and cell proliferation [12]. Recent experiments in animal models indicate that the cardiovascular system is the main target of the apelin - apelin receptor system $^{[13]}$.

We aimed in this study to find out the cardioprotective effect of apelin in a rat model of post MI and its effect on angiogenesis.

\section{Materials and Method}

\subsection{Animals}

Forty male albino Wistar rats of 8-12 weeks of age and weighing between $200-250 \mathrm{~g}$ were purchased from the animal house of Faculty of Medicine, Cairo University, Egypt. All procedures were approved by the Institutional Ethical Committee for Animal Care and Use of the Faculty of Medicine, Benha University. The animals were acclimatized over a week to standard laboratory conditions (22-24 ${ }^{\circ} \mathrm{C}$ surrounding temperature, 40 $60 \%$ relative humidity and $12-12 \mathrm{~h}$ light-dark cycle).

\subsection{Experimental design}

The animals were randomly divided into four equal groups $(n=10)$ : (a) Sham operated group (b) sham operated group + apelin-13 (c) MI group and (d) MI + apelin-13 group. MI was induced in rats by ligation of the left anterior descending coronary artery (LAD) as described earlier by Pfeffer et al. A left thoracotomy was performed via the 4th 
intercostal space, and the lungs were retracted to expose the heart. After the pericardium was opened, the LAD artery was ligated, $2 \mathrm{~mm}$ from its origin using a 4-0 silk (Ethicon, Johnson and Johnson, U.S.A.). Ligation was considered successful when the anterior wall of the LV turned pale. The chest was closed with a 2-0 silk (Ethicon, Johnson and Johnson, U.S.A.) after it was gently pressed to expel air from the cavity to avoid a pneumothorax. Once awake, the rats were injected intramuscularly with buprenorphine $\mathrm{HCl}(0.01 \mathrm{mg} / \mathrm{kg}$ body weight $)$ to reduce the pain during recovery. The sham operated group underwent a similar procedure except that the suture was not tightened around the LAD artery ${ }^{[14]}$. Apelin-13 (1.5 $\mu \mathrm{g} / \mathrm{kg} /$ day) or saline (Sigma, St Louis, MO, USA) were intraperitoneally (i.p.) injected after the onset of myocardial infarction once daily for 28 days ${ }^{[15]}$.

By the end of the experimental period, all rats were the rats were anesthetized by with xylazine (10 $\mathrm{mg} / \mathrm{kg}$ body weight) and Ketamine (100 mg/kg body weight) (Sigma, St Louis, MO, USA). Blood sample was drawn from the abdominal aorta and was allowed to clot at room temperature and sera were separated by centrifugation at $3000 \mathrm{rpm}$ for 15 min and stored at $-80^{\circ} \mathrm{C}$ for biochemical assessment of cardiac biomarkers and circulating angiogenic factors and the hearts were excised for assessment of the infarction size.

\subsection{Assessment of the infarction size}

The excised beating heart was submerged in cold $\mathrm{KCl}$ to achieve diastolic arrest. The right ventricle and both atria were excised to isolate the left ventricle. The left ventricle is sectioned into thin transverse slices and submerged in a $1.5 \%$ triphenyl tetrazolium chloride (TTC) stain in phosphate buffer, $\mathrm{PH} 7.4$, for 15 minutes at $37^{\circ} \mathrm{C}$. TTC stain form red color in the presence of intact dehydrogenase enzyme system thus the infarction areas were not stained red. TTC stained and nonstained areas were traced on clear plastic sheets fixed on an E.C.G paper to be counted in $\mathrm{mm} 2$. The infraction size \% was calculated as the total of infract area divided by the total of surface areas of all the slices ${ }^{[16]}$.

\subsection{Determination of cardiac biomarkers}

Serum lactate dehydrogenase (LDH) was determined enzymatically with pyruvate as substrate by using standard kits from (BioSystems S.A., Barcelona, Spain). Serum creatine kinase-MB (CK-MB) activity was assessed by an immuneinhibition method using standard kits from (BioSystems S.A., Barcelona, Spain) through the rate of NADPH formation by means of the hexokinase and glucose-6-phosphate dehydrogenase coupled reactions ${ }^{[17]}$.

\subsection{Insulin-like growth factor-1 (IGF-1),} transforming growth factor- $\beta$ (TGF- $\beta$ ) and vascular endothelial growth factor (VEGF) assay

Commercially available enzyme-linked immunosorbant assay (ELISA) kit (R\&D Systems, Inc., Minneapolis, MN, USA) was used in this assay. The micro titre plate provided in this kit was precoated with a primary antibody specific to each factor. Standards or samples are then added to the appropriate micro titre plate wells together with a biotin-conjugated specific secondary polyclonal antibody. Avidin conjugated to horseradish peroxidase and a 3,3'5,5' tetramethyl-benzidine substrate completed the immuno-reaction sequence that was ended with the addition of a sulphuric acid solution. Color change was measured at $450 \mathrm{~nm}{ }^{[17]}$.

\subsection{Statistical analysis}

All analyses were performed using the program Statistical Package for Social Sciences version 19 (SPSS Inc, Chicago, IL, USA). The data were presented as the mean (M) \pm standard deviation (SD). Comparisons between groups were analyzed by using one-way Analysis of Variance (ANOVA) followed by post-hoc LSD test. Probability of chance $(\mathrm{P}$ value $)<0.05$ was considered statistically significant.

\section{Results}

\subsection{Effect of Apelin-13 on the infarction size and cardiac biomarkers (CK-MB and LDH) (Table 1 and fig. 1 \& 2)}

The survival rates at the end of the observation of the rats were $100 \%(10 / 10)$ in the sham groups, $80 \%(8 / 10)$ in MI group and $90 \%(9 / 10)$ in the MI + apelin group respectively. Table 1 and figure 1 
showed that induction of MI resulted in significant increase in the infarction size from zero to $45.85 \pm$ $2.94(\mathrm{P}<0.05)$ while administration of apelin-13 in rats post MI caused significant decrease of the infarction size from $45.85 \pm 2.94$ to $10.13 \pm 0.82$ $(\mathrm{P}<0.05)$. Compared to the sham operated group, induction of MI of caused significant increase in the serum level of CK-MB and LDH as they were increased from $3.19 \pm 0.62 \mathrm{ng} / \mathrm{ml}$ and $24.87 \pm$
$3.48 \mathrm{IU} / \mathrm{L}$ to $27.75 \pm 1.24 \mathrm{ng} / \mathrm{ml}$ and $98.82 \pm 3.24$ $\mathrm{IU} / \mathrm{L}$ respectively $(\mathrm{P}<0.05)$. Administration of apelin-13 in rats post MI caused significant decrease of the elevated levels of serum CK-MB and $\mathrm{LDH}$ to $4.08 \pm 0.75$ and $39.59 \pm 3.94$ respectively $(\mathrm{P}<0.05)$ (table 1 and figure 2$)$. However, there was non-significant differences in CK-MB, LDH and infarction size between the sham operated group (group I) and sham operated + apelin 13 group (group II) $(\mathrm{P}>0.05)$.

Table 1: Effect of Apelin-13 on the infarction size and cardiac enzymes (CK-MB and LDH)

\begin{tabular}{|c|c|c|c|c|}
\hline Groups & $\begin{array}{c}\text { Group I } \\
\text { (Sham operated) }\end{array}$ & $\begin{array}{c}\text { Group II } \\
\text { (Sham operated + }\end{array}$ & $\begin{array}{l}\text { Group III } \\
\text { (MI) }\end{array}$ & $\begin{array}{c}\text { Group IV } \\
(\mathrm{MI}+\text { Apelin-13) }\end{array}$ \\
\hline Parameter & & & & \\
\hline Infarction size (\%) & 0 & 0 & $45.85 \pm 2.94^{*}$ & $10.13 \pm 0.82^{\$}$ \\
\hline CK-MB (ng/ml) & $3.19 \pm 0.62$ & $3.32 \pm 0.77$ & $27.75 \pm 0.24^{*}$ & $4.08 \pm 0.75^{\$}$ \\
\hline LDH (IU/L) & $24.87 \pm 3.48$ & $25.46 \pm 2.16$ & $98.82 \pm 3.24^{*}$ & $39.59 \pm 3.94^{\$}$ \\
\hline
\end{tabular}

The data were presented as the mean \pm standard deviation (SD). Comparisons between groups were analyzed by using one-way Analysis of Variance (ANOVA) followed by post-hoc LSD test. Probability of chance $(P$ value $)<$ 0.05 was considered statistically significant.

*Significant difference $v s$ the sham operated group

${ }^{\$}$ Significant difference $v s$ the MI.

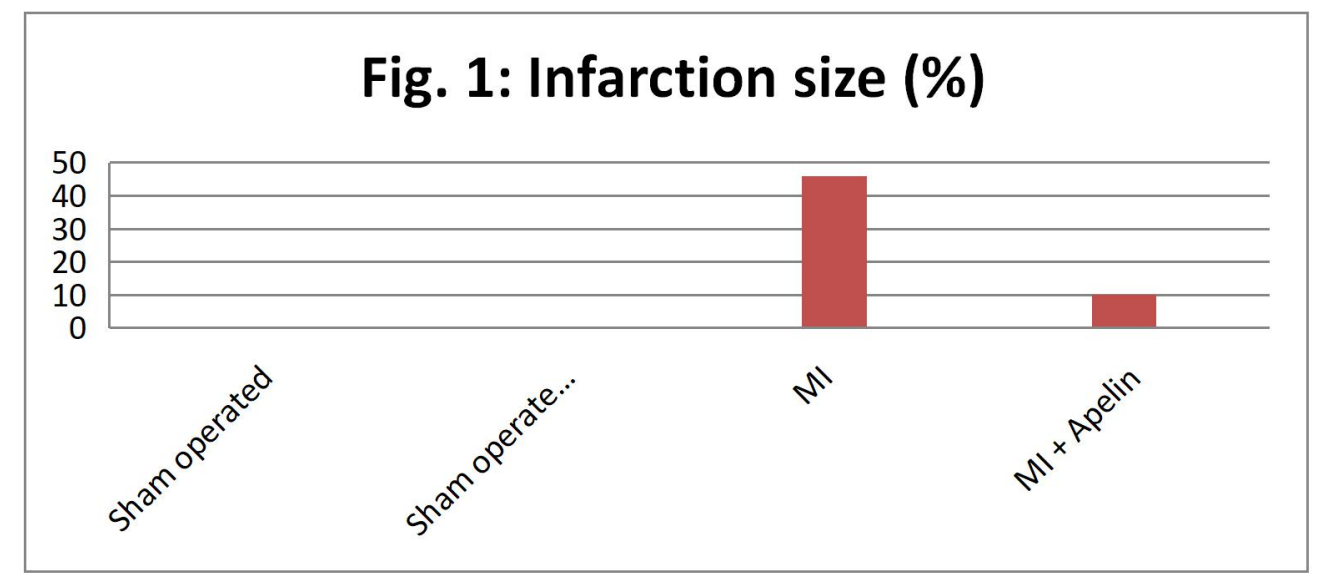

Figure 1: Infarction size (\%)

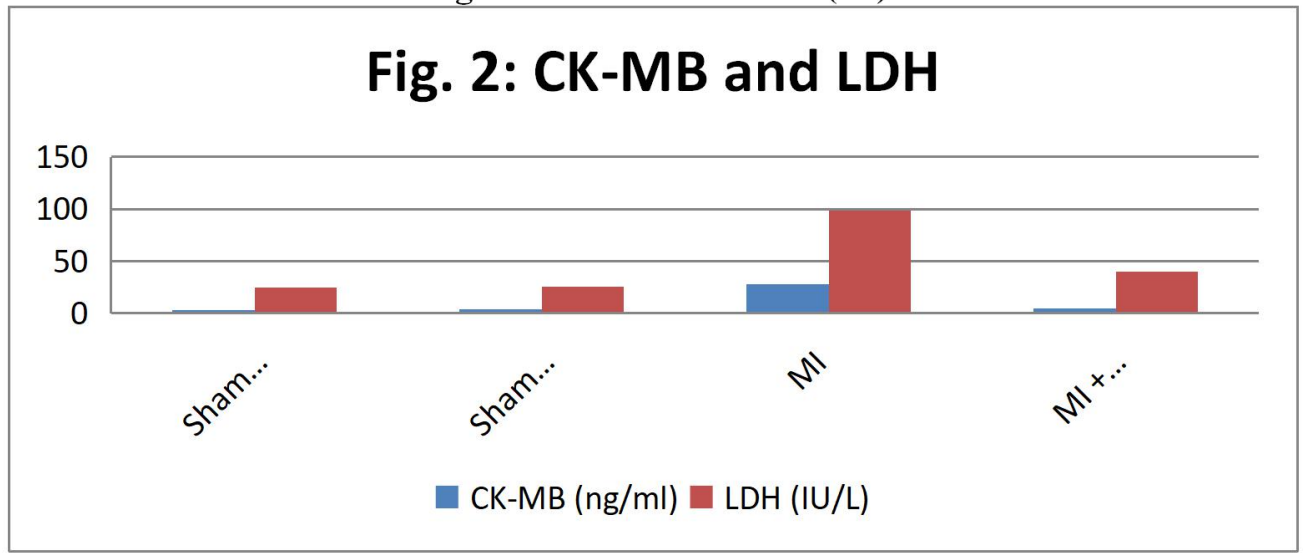

Figure 2: CK-MB and LDH 
3.2 Effect of Apelin-13 on circulating angiogenic factors (Table 2, fig. 3, $4 \& 5$ )

There was non-significant differences in circulating angiogenic factors (IGF-1, TGF- $\beta$ and VEGF between the sham operated group (group I) and sham operated + apelin 13 group (group II) (P > 0.05 ). Induction of MI caused significant increase in the serum levels of circulating angiogenic factors when compared with sham operated group as IGF-1 was increased from $3.44 \pm 0.46$ to $9.86 \pm 0.92$ $\mathrm{ng} / \mathrm{ml}$, TGF- $\beta$ was increased from $6.33 \pm 0.88$ to $12.67 \pm 0.77 \mathrm{ng} / \mathrm{ml}$ and VEGF was increased from $145.09 \pm 4.80$ to $244.50 \pm 9.83 \mathrm{pg} / \mathrm{ml}(\mathrm{P}<0.05)$ with further increase with apelin treatment in the infarct rats to reach $15.76 \pm 0.76,19.13 \pm 0.99$ and $338.77 \pm 9.56$ respectively $(\mathrm{P}<0.05)$.

Table 2: Effect of Apelin-13 on circulating angiogenic factors

\begin{tabular}{|c|c|c|c|c|}
\hline Groups & $\begin{array}{c}\text { Group I } \\
\text { (Sham operated) }\end{array}$ & $\begin{array}{c}\text { Group II } \\
\text { (Sham operated } \\
\text { group + Apelin-13) }\end{array}$ & $\begin{array}{c}\text { Group III } \\
\text { (MI) }\end{array}$ & $\begin{array}{c}\text { Group IV } \\
\text { (MI + Apelin-13) }\end{array}$ \\
\hline Parameter & $3.44 \pm 0.46$ & $4.24 \pm 0.84$ & $9.86 \pm 0.92^{*}$ & $15.76 \pm 0.76^{\$}$ \\
\hline IGF-1 (ng/ml) & $6.33 \pm 0.88$ & $7.28 \pm 0.48$ & $12.67 \pm 0.77^{*}$ & $19.13 \pm 0.99^{\$}$ \\
\hline VEGF (ng/ml) & $145.09 \pm 4.80$ & $147.12 \pm 7.29$ & $244.50 \pm 9.83^{*}$ & $338.77 \pm 9.56^{\$}$ \\
\hline
\end{tabular}

The data were presented as the mean \pm standard deviation (SD). Comparisons between groups were analyzed by using one-way Analysis of Variance (ANOVA) followed by post-hoc LSD test. Probability of chance $(P$ value $)<$ 0.05 was considered statistically significant.

* Significant difference $v s$ the sham operated group

$\$$ Significant difference $v s$ the MI group.

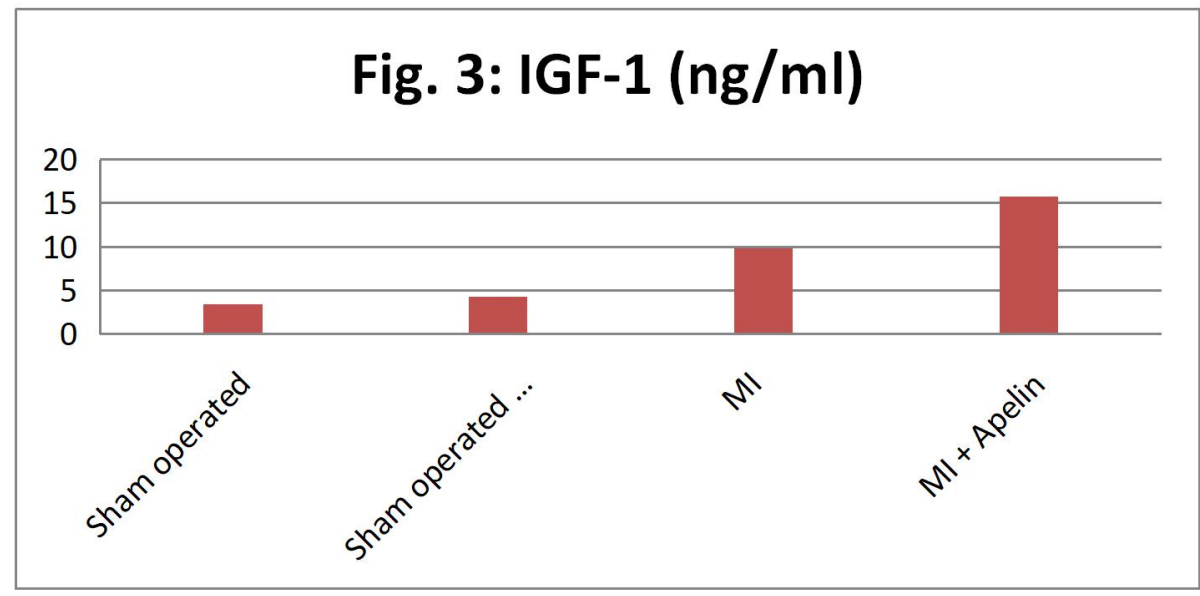

Figure 3: IGF-1 (ng/ml)

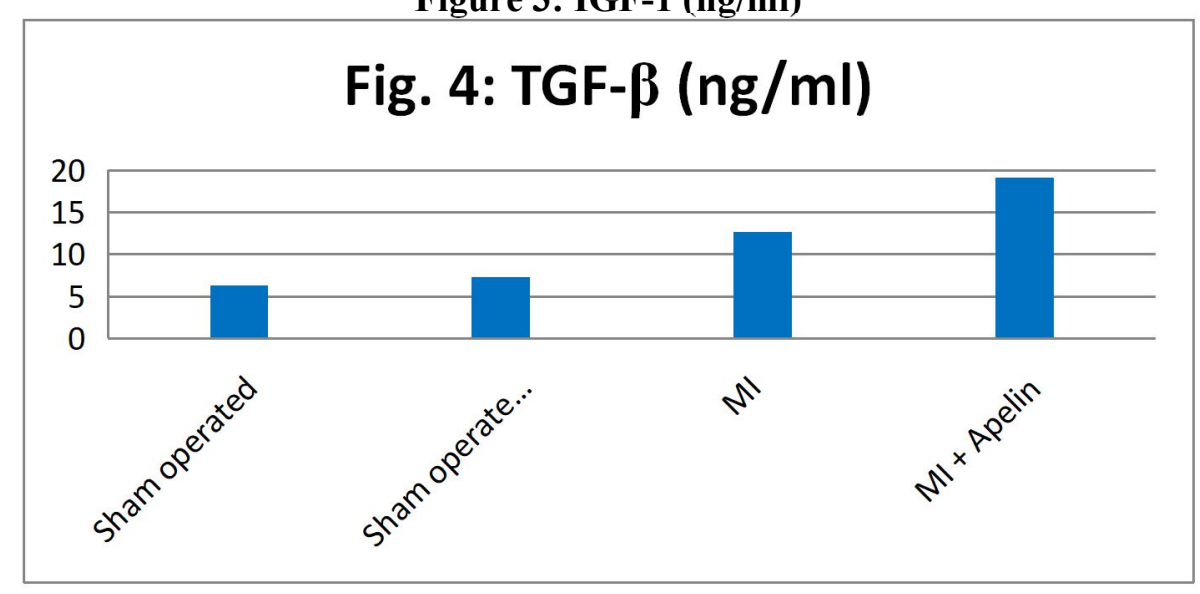

Figure 4: TGF- $\beta$ (ng/ml) 


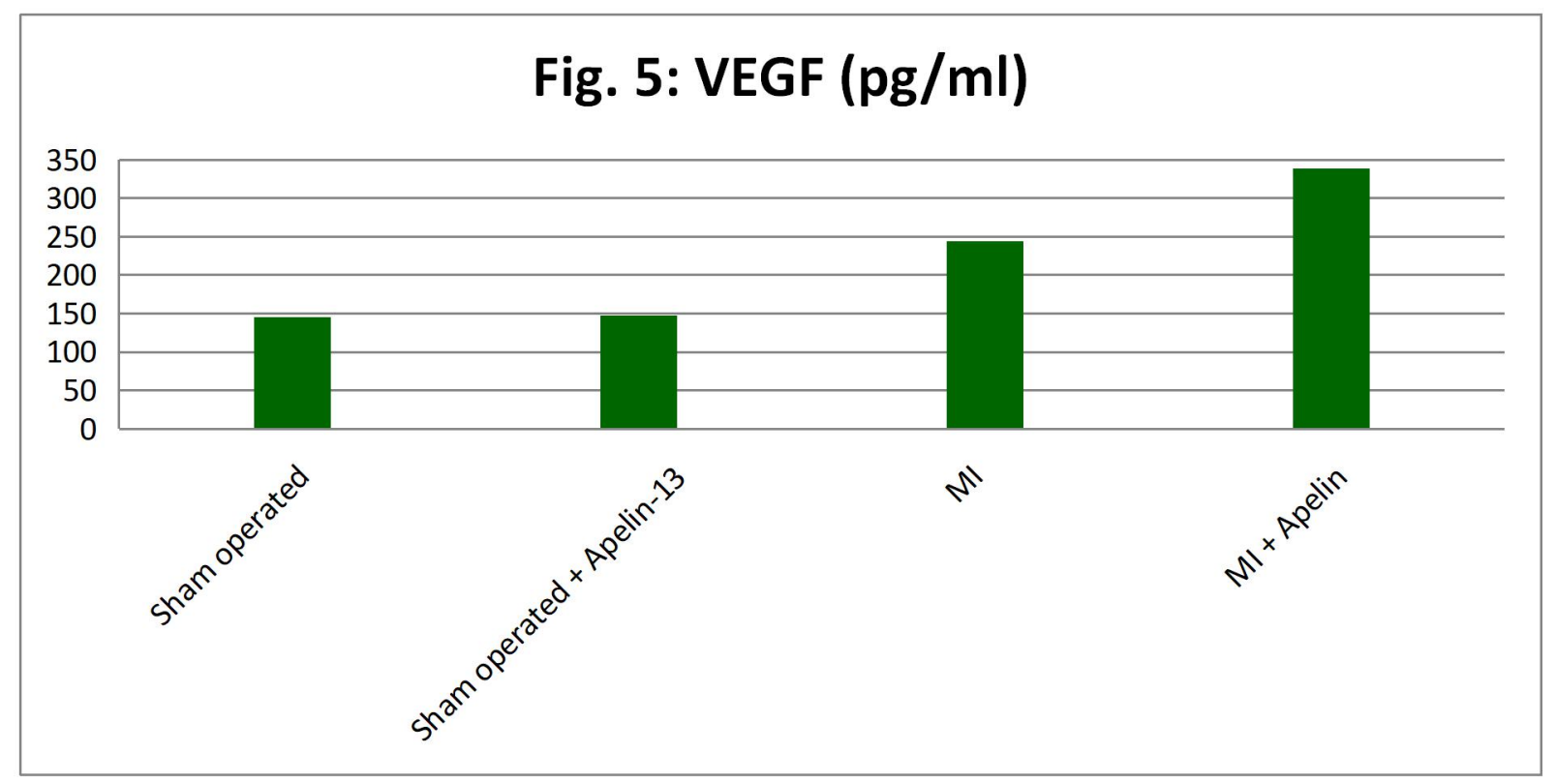

Figure 5: VEGF (pg/ml)

\section{Discussion}

The present work evaluated the cardioprotective effect of apelin-13 in a rat model of myocardial ischemia, exploring its effects on angiogenesis and functional recovery. In the present study, the left anterior descending artery was ligated to establish acute myocardial ischemia. This led to a significant increase in the infarction size and the myocardial enzymes, including CK-MB and LDH. This result was in agreement to the previous studies $[18,19]$. The present work also revealed that circulating levels of angiogenic factors (TGF- $\beta$ and VEGF) and the proangiogenic growth factor (IGF-1) were significantly increased in the MI group when compared to the sham operated group. Ischemic injury is known to stimulate the release of angiogenic factors derived from the local tissue into the blood circulation ${ }^{[20,21,22]}$ and this could be an adaptive response for revascularization and repair of the myocardium to maintain adequate oxygen supply after myocardial ischemia ${ }^{[23]}$. VEGF is rapidly induced in the ischemic heart in both rodents and humans ${ }^{[12,24]}$. Rabinovsky et al. pointed that stimulation of angiogenesis by VEGF that occurred after ischemia helped in the regulation of endothelial cell proliferation and migration as well as cell survival ${ }^{[25]}$. TGF- $\beta$ also played a major role in angiogenesis by stimulating extracellular matrix production, stabilizing newly formed blood vessels and influencing the expression of other angiogenic factors ${ }^{[26]}$. The proangiogenic growth factor; IGF-1 promoted angiogenesis by stimulating the release of other angiogenic factors such as VEGF and TGF- $\beta$ [17].

In acute myocardial ischemia, apelin may have a protective role. The results of the present work revealed that administration of apelin-13 in the MI group led to significant reduction in the infarction size and cardiac biomarkers; CK- MB and LDH. Our results are in congruent to the previous studies which revealed that apelin administration attenuated myocardial injury induced by isoproterenol overdose ${ }^{[27]}$ or left anterior descending coronary artery ligation in rats ${ }^{[15]}$. In vitro and vivo experimental studies have observed that apelin and apelin receptor gene expression were up-regulated in response to myocardial infarction in cardiac and peripheral tissue ${ }^{[28,29]}$. Exogenous apelin infusion improved cardiac contractility, suggesting that the endogenous apelin production was insufficient to activate all the apelin receptors. Therefore, the apelin - apelin receptor system may be induced in ischemia to limit myocardial injury ${ }^{[30,31]}$. In mouse hearts, a reduction in infarction size resulting from occlusion of the left descending coronary artery occurred to a greater extent with apelin-13 and to a lesser extent with apelin-36 $[15,32,33]$. In the isolated rat heart, the size of a MI caused by $35 \mathrm{~min}$ of occlusion of the left main coronary artery was significantly reduced if exogenous apelin solution was infused for $20 \mathrm{~min}^{[34]}$. 
Increased angiogenesis and the formation of new blood vessels are critical processes in the restoration of coronary blood flow and in the repair of ischemic injury post MI ${ }^{[35]}$. The present work also showed that post-infarction treatment with apelin-13 significantly increased the serum levels of angiogenic factors (IGF-1, TGF- $\beta$ and VEGF). Previous reports showed that apelin increased VEGF/VEGFR2, and angiopoietin-1 (Ang-1)/Tie-2 expression and the density of capillary and arteriole density in the heart ${ }^{[36]}$. Li et al. found that treatment with apelin-13 resulted in a significant improvement of cardiac function post-MI, promoted myocardial angiogenesis and ameliorated cardiac fibrosis and hypertrophy by a mechanism involving the upregulation of stromal cell derived factor (SDF)$1 \alpha /$ chemokine receptor (CXCR)- 4 and homing of vascular progenitor cells (PCs) ${ }^{[37]}$. An increasing number of evidences demonstrated that angiogenic growth factors have been shown to reduce infarct size, increased vascularity and improve left ventricular ejection fraction in animal models of acute $\mathrm{MI}{ }^{[38]}$.

\section{Conclusion and Recommendations}

Apelin-13 enhanced circulating levels of angiogenic factors; IGF-1, TGF- $\beta$ and VEGF together with reduction of the enzymes associated with cardiac injury (CK-MB and LDH) and infarction size in rats with induced myocardial infarction. Apelin-13 may enhance neovascularization attributable to the increased presence of angiogenic factors thus it seems to be a novel and efficient therapeutic strategy for myocardial infarction in humans.

\section{List of abbreviations}

CK-MB， Creatinine kinase-MB; CXCR, Chemokine receptor; ELISA, enzyme linked immunosorbent assay; IGF-1, Insulin like growth factor one; IHD, Ischemic heart disease; i.p., intraperitoneal; LDH, Lactate dehydrogenase; MI, Myocardial infarction; PC, Progenitor cells; SDF, Stromal cell derived factor; TGF- $\beta$, Transforming growth factor beta; TTC, Triphenyl tetrazolium chloride; VEGF, Vascular endothelial growth factor.

\section{Conflict of interest}

The author declares that there is no conflict of interest.

\section{References}

1 Farvin KH, Anandan R, Kumar SH, Shiny KS, Mathew S, Sankar TV, Nair PG. Cardioprotective effect of squalene on lipid profile in isoprenaline-induced myocardial infarction in rats. $J$ Med Food 2006; 9(4): 531536 DOI: $10.1089 /$ jmf.2006.9.531

2 Thiagarajan $\mathrm{H}$, Thiyagamoorthy $\mathrm{U}$, Shanmugham I, Dharmalingam Nandagopal G, Kaliyaperumal A. Angiogenic growth factors in myocardial infarction: a critical appraisal. Heart Fail Rev 2017; 22(6): 665-683 [PMID: 28639006 DOI: 10.1007/s10741-017-9630-7]

3 Jugdutt BI.Ischemia/Infarction.Heart Fail Clin 2012; 8(1): 43-51 [PMID: 22108726 DOI: 10.1016/j.hfc.2011.08.006]

4 Verdouw, P.D.; van den Doel, M.A.; de Zeeuw, S.; Duncker, D.J. Animal Models in the Study of Myocardial Ischaemia and Ischaemic Syndromes. Cardiovasc. Res. 1998, 39, 121135. DOI: $\underline{10.1016 / \mathrm{s} 0008-6363(98) 00069-8}$

5 Markkanen JE, Rissanen TT, Kivela A, YlaHerttuala S. Growth factor-induced therapeutic angiogenesis and arteriogenesis in the heartgene therapy. Cardiovasc Res 2005; 65(3): 656-664

DOI:

10.1016/j.cardiores.2004.10.030

6 Folkman J. Angiogenesis in cancer, vascular, rheumatoid and other disease. Nat Med 1995; 1(1): 27-31 DOI: $10.1038 / \mathrm{nm} 0195-27$

7 Bougioukas I, Didilis V, Ypsilantis $\mathrm{P}$, Giatromanolaki A, Sivridis E, Lialiaris T, Mikroulis D, Simopoulos C, Bougioukas G. Intramyocardial injection of low-dose basic fibroblast growth factor or vascular endothelial growth factor induces angiogenesis in the infarcted rabbit myocardium. Cardiovasc Pathol 2007; 16(2): 63-68 [PMID: 17317537 DOI: $10.1016 /$ j.carpath.2006.08.006]

8 Sui X, Gao C. Huperzine A ameliorates damage induced by acute myocardial infarction in rats through antioxidant, antiapoptotic and anti-inflammatory mechanisms. 
Int J Mol Med 2014; 33(1): 227-233 [PMID: 24190328 DOI: 10.3892/ijmm.2013.1546]

9 Lee, D.K.; Cheng, R.; Nguyen, T.; Fan, T.; Kariyawasam, A.P.; Liu, Y.; O'Dowd, B.F. Characterization of apelin, the ligand for the APJ receptor. J. Neurochem. 2000, 74(1), 34 41. https://doi/full/10.1046/j.14714159.2000.0740034.x

10 Tatemoto K, Hosoya M, Habata Y, Fujii R, Kakegawa T, Zou MX, Kawamata Y, Fukusumi S, Hinuma S, Kitada C, Kurokawa T, Onda H, Fujino M. Isolation and characterization of a novel endogenous peptide ligand for the human APJ receptor. Biochem Biophys Res Commun 1998; 251(2): 471-476 DOI: $10.1006 /$ bbrc. 1998.9489

11 Folino A, Montarolo PG, Samaja M, Rastaldo R. Effects of apelin on the cardiovascular system. Heart Fail Rev 2015; 20(4): 505-518 DOI: $10.1007 / \mathrm{s} 10741-015-9475-\mathrm{x}$

12 Lee SH, Wolf PL, Escudero R, Deutsch R, Jamieson SW, Thistlethwaite PA. Early expression of angiogenesis factors in acute myocardial ischemia and infarction. $N$ Engl $\boldsymbol{J}$ Med 2000; 342(9): 626-633 [PMID: 10699162 DOI: 10.1056/NEJM200003023420904]

13 Tycinska AM, Lisowska A, Musial WJ, Sobkowicz B. Apelin in acute myocardial infarction and heart failure induced by ischemia. Clin Chim Acta 2012; 413(3-4): 406-410 DOI: 10.1016/j.cca.2011.11.021

14 Pfeffer MA, Pfeffer JM, Fishbein MC, Fletcher PJ, Spadaro J, Kloner RA, Braunwald E. Myocardial infarct size and ventricular function in rats. Circ Res 1979; 44(4): 503-512 [PMID: 428047 DOI: 10.1161/01.res.44.4.503]

15 Zhang BH, Guo CX, Wang HX, Lu LQ, Wang YJ, Zhang LK, Du FH, Zeng XJ. Cardioprotective effects of adipokine apelin on myocardial infarction. Heart Vessels 2014; 29(5): 679-689 DOI: 10.1007/s00380-013$\underline{0425-\mathrm{z}}$

16 Evans RG, Val-Mejias JE, Kulevich J, Fischer VW, Mueller HS. Evaluation of a rat model for assessing interventions to salvage ischaemic myocardium: effects of ibuprofen and verapamil. Cardiovasc Res 1985; 19(3): 132138 DOI: $\underline{10.1093 / \mathrm{cvr} / 19.3 .132}$
17 Lisa M, Haleagrahara N, Chakravarthi S. Insulin-Like Growth Factor-1 (IGF-1) Reduces ischemic changes and increases circulating angiogenic factors in experimentally - induced myocardial infarction in rats. Vasc Cell 2011; 3(1): 13 DOI: $10.1186 / 2045-824 X-3-13$

18 Wang, H.; Cao, C.; Hui, L.; Liu, T.; Wang, Y.; Gao, S.; Zhang, Y.; Hao, R.; Li, C.; Zang C. A Study of Myocardial Ischemia Model Induced by Left Coronary Artery Ligation in Rats. World J. Cardiovasc. Dis. 2016, 6, 133-142. DOI: $10.4236 /$ wjed.2016.65014

19 Tian,W.;Feng-Hua School of Pharmacy, Yantai University, Yantai, China, F.; Bing School of Pharmacy, Yantai University, Yantai, China, H.; Gui-Sheng School of Pharmacy, Yantai University, Yantai, China, L.; Lei-Ming School of Pharmacy, Yantai University, Yantai, China, Z.; Ke, L. Hydroxysafflor yellow A reduces myocardial infarction size after coronary artery ligation in rats. Pharmaceutical Biology. 2009, 47(5), 458-462. DOI: $10.1080 / 13880200902822612$

20 Korpisalo P, Yla-Herttuala S. Stimulation of functional vessel growth by gene therapy. Integr Biol (Camb) 2010; 2(2-3): 102-112 [PMID: 20473388 DOI: 10.1039/b921869f]

21 Yla-Herttuala S, Rissanen TT, Vajanto I, Hartikainen J. Vascular endothelial growth factors: biology and current status of clinical applications in cardiovascular medicine. $\boldsymbol{J} \mathbf{A m}$ Coll Cardiol 2007; 49(10): 1015-1026 [PMID: 17349880 DOI: $10.1016 /$ j.jacc.2006.09.053]

22 Kastrup J.Therapeutic angiogenesis in ischemic heart disease: gene or recombinant vascular growth factor protein therapy?. Curr Gene Ther. 2003, 3(3), 197-206. DOI: $\underline{10.2174 / 1566523034578366}$

23 Senter, S.; Francis, G.S. A new, precise definition of acute myocardial infarction. Cleve Clin. J. Med. 2009, 76(3), 159 - 166. DOI: 10.3949/ccjm.75a.08092

24 Hashimoto, E.; Ogita, T.; Nakaoka, T.; Matsuoka, R.; Takao, A.; Kira Y. Rapid induction of vascular endothelial growth factor expression by transient ischemia in rat heart. Am. J. Physiol. 1994, 267, H1948 - H1954. DOI: 10.1152 ajpheart.1994.267.5.H1948 
25 Rabinovsky ED. The multifunctional role of IGF-1 in peripheral nerve regeneration. Neurol Res 2004; 26(2): 204-210 [PMID: 15072640 DOI: $10.1179 / 016164104225013851]$

26 Ma J, Wang Q, Fei T, Han JD, Chen YG. MCP-1 mediates TGF-beta-induced angiogenesis by stimulating vascular smooth muscle cell migration. Blood 2007; 109(3): 987-994 DOI: $10.1182 /$ blood-2006-07-036400

27 Jia YX, Pan CS, Zhang J, Geng B, Zhao J, Gerns H, Yang J, Chang JK, Tang CS, Qi YF. Apelin protects myocardial injury induced by isoproterenol in rats. Regul Pept 2006; 133(13): 147-154 DOI: 10.1016/j.regpep.2005.09.033

28 Sheikh AY, Chun HJ, Glassford AJ, Kundu RK, Kutschka I, Ardigo D, Hendry SL, Wagner RA, Chen MM, Ali ZA, Yue P, Huynh DT, Connolly AJ, Pelletier MP, Tsao PS, Robbins RC, Quertermous T. In vivo genetic profiling and cellular localization of apelin reveals a hypoxia-sensitive, endothelialcentered pathway activated in ischemic heart failure. Am J Physiol Heart Circ Physiol 2008; 294(1): H88-98

DOI: 10.1152/ajpheart.00935.2007

29 Ronkainen VP, Ronkainen JJ, Hanninen SL, Leskinen H, Ruas JL, Pereira T, Poellinger L, Vuolteenaho O, Tavi P. Hypoxia inducible factor regulates the cardiac expression and secretion of apelin. FASEB $\boldsymbol{J}$ 2007; 21(8): 1821-1830 DOI: 10.1096/fj.06-7294com

30 Atluri P, Morine KJ, Liao GP, Panlilio CM, Berry MF, Hsu VM, Hiesinger W, Cohen JE, Joseph Woo Y. Ischemic heart failure enhances endogenous myocardial apelin and APJ receptor expression. Cell Mol Biol Lett 2007; 12(1): 127-138 DOI: $\underline{10.2478 / \mathrm{s} 11658-}$ 006-0058-7

31 De Mota N, Lenkei Z, Llorens-Cortes C. Cloning, pharmacological characterization and brain distribution of the rat apelin receptor. Neuroendocrinology 2000; 72(6): 400-407 [PMID: 11146423 DOI: 10.1159/000054609]

32 Simpkin JC, Yellon DM, Davidson SM, Lim SY, Wynne AM, Smith CC. Apelin-13 and apelin-36 exhibit direct cardioprotective activity against ischemia-reperfusion injury.
Basic Res Cardiol 2007; 102(6): 518-528 DOI: $10.1007 / \mathrm{s} 00395-007-0671-2$

33 Smith CC, Mocanu MM, Bowen J, Wynne AM, Simpkin JC, Dixon RA, Cooper MB, Yellon DM. Temporal changes in myocardial salvage kinases during reperfusion following ischemia: studies involving the cardioprotective adipocytokine apelin. Cardiovasc Drugs Ther 2007; 21(6): 409-414 [PMID: 17924178 DOI: 10.1007/s10557-007-6054-y]

34 Kleinz MJ, Baxter GF. Apelin reduces myocardial reperfusion injury independently of PI3K/Akt and P70S6 kinase. Regul Pept 2008; 146(1-3): 271-277 [PMID: 18022257 DOI: 10.1016/j.regpep.2007.10.002]

35 Sasaki H, Fukuda S, Otani H, Zhu L, Yamaura G, Engelman RM, Das DK, Maulik N. Hypoxic preconditioning triggers myocardial angiogenesis: a novel approach to enhance contractile functional reserve in rat with myocardial infarction. J Mol Cell Cardiol 2002; 34(3): 335-348 DOI: 10.1006/jmcc.2001.1516

36 Zeng, H.; He, X.; Hou, X.; Li, L.; Chen, J.X. Apelin gene therapy increases myocardial vascular density and ameliorates diabetic cardiomyopathy via upregulation of sirtuin 3 . Am. J. Physiol. Heart Circ. Physiol. 2014, 306(4), H585 -97. DOI: 10.1152/ajpheart.00821

37 Li L, Zeng H, Chen JX. Apelin-13 increases myocardial progenitor cells and improves repair postmyocardial infarction. Am J Physiol Heart Circ Physiol 2012; 303(5): H605-618 [PMID: 22752632 PMCID: PMC3468469 DOI: 10.1152/ajpheart.00366.2012]

38 Yanagisawa-Miwa A, Uchida Y, Nakamura F, Tomaru T, Kido H, Kamijo T, Sugimoto T, Kaji K, Utsuyama M, Kurashima C, et al. Salvage of infarcted myocardium by angiogenic action of basic fibroblast growth factor. Science 1992; 257(5075): 1401-1403 [PMID: 1382313 DOI: $\underline{10.1126 / \text { science. } 1382313}$ ] 